http://dx.doi.org/10.35630/2199-885X/2020/10/3.7

\title{
AGE-RELATED VARIABILITY OF SOMATOTYPE FEATURES IN FEMALES
}

\section{Yulia Kustova ${ }^{1}$, Natalya Chelnokova ${ }^{2 凶}$ (D), Nikolay Yakovlev $^{3}$ (D), Elena Anisimova ${ }^{1}$ (D), Valery Konnov ${ }^{4}$ (iD}

\section{${ }^{1}$ Human Anatomy Department, Saratov State Medical University, Saratov ${ }^{2}$ Department of Operative Surgery and Topographic Anatomy, Saratov State Medical University, Saratov \\ ${ }^{3}$ Saratov Hygiene Medical Research Center of the FBSI «FSC Medical and Preventive Health Risk Management Technologies», Saratov ${ }^{4}$ Department of Orthopedic Dentistry; Saratov State Medical University, Saratov, Russia}

\section{nachelnokova@yandex.ru}

Received 15 July 2020;

Received in revised form 25 August 2020; Accepted 28 August 2020

\section{INTRODUCTION}

The constitution typology of the human body refers to a relevant subject dealing with the current progress of the medical science. At the same time, the anthropological area in terms of research has been developing fast. The subject of study for morphologists now is the somatic type for normal and various pathological conditions. The somatic type, which is shaped through the heredity program within a specific environment, reflects the level and the harmony of physical development, both for the individual and the population taken as a whole [11-16].

Currently, anthropometric methods are widely employed in preventive medicine, which is done both to identify the risk groups and to assess the effectiveness of preventive measures $[8,9]$. By the age of 18-20, people mostly stop growing, and until the age of 30 the length of the body reveals only a slight increase (up to $0.5 \mathrm{~cm}$ per year), which is largely due to the spine lengthening. At the age of 30-50, the body length remains constant, and then it decreases gradually (by about $1 \mathrm{~cm}$ over 10 years) [4], which mainly happens through the spine shortening because of its increased bending, reduced elasticity and flattening of the intervertebral discs, as well as due to emerging osteoporosis [9]. Since the growth of the human body individual parts is uneven, the body proportions change over time. The body weight is one of the most important indicators of the physical development, and it depends on the age, the body morpho-functional features, and allows making some indirect judgment concerning the health status. The body mass index (BMI) is calculated as the ratio of the body weight $(\mathrm{kg})$ to the body length $\left(\mathrm{m}^{2}\right)$ : BMI = body weight $(\mathrm{kg}) /$ body length $\left(\mathrm{m}^{2}\right)$. The BMI allows an objective assessment of the individual's nutrition status, and is an important indicator when it comes to evaluating the risk of developing certain diseases associated with the body weight $[1,2,3]$.

The waist circumference is a reliable indicator of excess fat accumulated in the abdominal area (abdominal fat). In females, the waist circumference exceeding $88 \mathrm{~cm}$ is a risk factor signaling potential development and progression of CAD and type II diabetes. The waist-to-hip ( $\mathrm{W} / \mathrm{H}$ index) is a simple indicator of the fat distribution pattern $[6,7]$. Obesity, especially

KEYW ORDS - age variability, women, physique, somatotype. 
abdominal, is a risk factor behind diabetes and cardiovascular diseases [10]. An increase in the $\mathrm{W} / \mathrm{H}$ index is of a protective effect that it has on the bone tissue, and is a factor in osteoporosis development [3].

Based on the somatic status analysis involving healthy people, a classification of somatotypes has been proposed, the basis of that being the ratio of the human body tissues developing from three primitive tissue layers - endo-, meso- and ectoderm. The endomorphic type can be described as featuring predominance of organs that develop based on the inner layer (internal organs and adipose tissue). The mesomorphic somatotype features the predominance of derivatives coming from the mid-layer, which is the basis for the skeleton and muscles. The ectomorphic type reveals the predominance of the outer leaf, from which the nervous system and integument develop [5].

\section{Aim of study:}

to identify the physique and somatotype variability patterns for females aged 18-50 residing in the Saratov Region.

\section{MATERIALS AND METHODS}

The study included women aged 18-50 ( $\mathrm{n}=178)$ residing in the Saratov Region, who underwent bioimpedance diagnostics at the Center for Medical Prevention (City of Engels, Russia). The participants were divided into groups: Group I, 18-20 years old, 37 participants; Group II, 21-30 years old, 41 participants; Group III, 31-40 years old, 43 participants; Group IV, 41-50 years old, 57 participants [4]. The methods used included anthropo- and bioimpedansometry [7]. The following indices were identified: age (A, years), body length (BL, cm), body weight (BW, $\mathrm{kg}$ ), waist circumference $(\mathrm{W}, \mathrm{cm})$, hip circumference $(\mathrm{H}, \mathrm{cm})$, body mass index $(\mathrm{BMI})$, waist-to-hip ratio $(\mathrm{W} / \mathrm{H})$, endo- (viscerotonia), ecto- (cerebrotonia) and mesomorphy (somatotonia) indices.

The variation and statistical processing of the outcomes was performed using the Statistica 10.0 application software package. The distribution normality was checked using the Shapiro-Wilk test. Given that the groups differed in the number of participants, as well as due to the fact that the distribution of features does not always follow the normal distribution pattern, the median (Me), 25 and $75 \%$ percentiles were identified [25.0 75.0]. The statistical significance of differences was calculated through the Mann-Whitney test. The differences were considered statistically significant at 95 and $99 \%$ probability limits. Besides, correlation analysis was applied, where correlations were considered strong (tight) at $r>0.75$; significant - at $r$ ranging from 0.5 to 0.75 ; average - at $\mathrm{r}$ falling within the range of 0.25 to 0.49 ; weak - at $r<0.25$; the variation and extensiveness coefficients were identified.

\section{RESULTS AND DISCUSSION}

The body length of adolescent females (Group I) featured on average of $163.5 \mathrm{~cm}$; in Groups II and III it was slightly more (by 0.9 and $0.7 \%$, respectively); in Group IV - less by 1.4\% compared to Group III (the differences in adjacent groups were statistically insignificant, $p>0.05)$. The body weight showed a statistically significant increase $(\mathrm{p}<0.01)$ changing from $55.0 \mathrm{~kg}$ in Group I by $11.0 \%$ in Group II and $15.7 \%$ in Group III, and basically revealed no change in Group IV if matched against Group III $(\mathrm{p}=0.4)$. The BMI also went up every 10 years - starting from 20.6 in the youth group, and going up 9.6; 15.5 and 2.9\%; the differences between Groups I and II, II and III proved statistically significant $(\mathrm{p}<0.05)$, while between Groups III and IV they were insignificant $(\mathrm{p}=0.4)$. In case of the adolescent period, the majority of the females $(81.5 \%)$ had BMI values within the normal range; $14.8 \%$ of the cases had weight deficit, while 3.7\% proved overweight; in Group II the share of those with the body mass deficit persisted; the number of females with normal index values decreased, while the number of those overweight increased; in Groups I and II no obese cases were observed.

The group of those aged 31-40 featured an equal distribution of females with normal BMI values and those who were overweight (37.2\%); the number of participants with a body mass deficit went down significantly, and then there appeared participants with obesity (Degree I and II; 11.6\%). The group of females aged $41-50$ had no persons with a body mass deficit; one third of the group had a normal body weight, 38.9\% were overweight, as well as there were patients with obesity of Degree I - 18.5\%; II $5.6 \%$, III $-3.7 \%$. The results obtained were partially compared with the outcomes of the study conducted by N.N. Tyatenkova et al. (2018) involving residents of the Yaroslavl Region, while that study, too, relied on the age-based periodization of 10 years. The BW in the group of females aged 20-29 was $61.2 \mathrm{~kg}$ (according to our data -61.8 in females aged $21-30)$; in those aged $30-39$ the BW was $67.9 \mathrm{~kg}(73.3 \mathrm{~kg})$, while 40-49-year-old participants had a BW of $72.0 \mathrm{~kg}(73.1$ $\mathrm{kg})$ (see Table 1).

The waist circumference increased up to the age of 40 , changing from $63.4 \mathrm{~cm}$ in the youth group to $80.0 \mathrm{~cm}$ (the inter-group differences were statistically significant $(\mathrm{p}<0.001)$ and goes on increasing slightly in Group IV. The differences, though, do not come to be statistically significant $(\mathrm{p}=0.6)$. The hip circumference also increases by the age of 30 years $(+3.5 \%$; 
Table 1. Age-related anthropometric and bioimpedance variability in females aged 18-50

\begin{tabular}{|c|c|c|c|c|}
\hline \multirow{2}{*}{ Index } & \multicolumn{4}{|l|}{ Age groups } \\
\hline & 1 & II & III & IV \\
\hline A (yrs) & $18.8[18.019 .0]^{*}$ & $25.6[23.029 .0]^{*}$ & $35.7[33.038 .0]^{* *}$ & $46.9[45.049 .0]^{* * *}$ \\
\hline $\mathrm{BL}(\mathrm{cm})$ & $163.5\left[\begin{array}{lll}160.0 & 167.0]\end{array}\right.$ & $164.9[160.0168 .0]$ & $164.6[161.0169 .0]$ & $162.3[157.0167 .0]$ \\
\hline BW (kg) & $55.0[48.161 .9]^{*}$ & $61.8[53.267 .1]^{*}$ & $73.3[59.280 .1]^{* *}$ & 73.1 [63.081.0] \\
\hline $\mathrm{BMI}$ & $20.6[18.722 .4]^{*}$ & $22.8[19.524 .4]^{*}$ & $27.0[22.529 .8]^{* *}$ & $27.8[24.231 .1]$ \\
\hline$W(\mathrm{~cm})$ & $63.4[60.066 .0]^{*}$ & $71.5[65.075 .0]^{*}$ & $80.0[70.088 .0]^{* *}$ & $81.3[73.087 .0]$ \\
\hline $\mathrm{H}(\mathrm{cm})$ & $91.4[87.096 .0]^{*}$ & $94.7[90.099 .0]^{*}$ & $103.3[96.0107 .0]^{* *}$ & $103.2[98.0110 .0]$ \\
\hline W/H & $0.69[0.670 .73]^{*}$ & $0.75[0.710 .79]^{*}$ & $0.77[0.710 .83]$ & $0.79[0.730 .82]$ \\
\hline Endo- & $1.07[0.551 .49]^{*}$ & $1.61[0.901 .88]^{*}$ & $2.45[1.403 .03]^{* *}$ & $2.61[1.743 .45]$ \\
\hline Exo- & $6.21[5.856 .58]^{*}$ & $6.52[6.256 .70]{ }^{*}$ & $6.86[5.357 .32]^{* *}$ & 6.78 [6.317.17] \\
\hline Meso- & $4.29[4.214 .42]^{*}$ & $4.42[4.314 .53]^{*}$ & $4.62[4.384 .71]]^{* *}$ & 4.58 [4.42 4.70] \\
\hline
\end{tabular}

Note. * _ statistically significant age-related differences among the groups $\left({ }^{*}\right.$ — between Groups I and II, ** — II and III, *** — III and IV).

$\mathrm{p}=0.05)$, and then within the next 10 years - by $8.3 \%$ $(p=0.001)$, whereas in Group IV it reveals basically no change $(p=0.9)$. The $\mathrm{W} / \mathrm{H}$ index is one of the most reliable indicators of females' health and fertility, as well as it is the aesthetic optimum, which is a reliably indicating of the reproductive status and reproductive capacity. Given the effect of estrogen, fat accumulation in the abdomen is suppressed, while it is stimulated (gynoid fat) at the thighs and buttocks, serving an energy reserve for pregnancy and subsequent lactation. Depending on this index value, there are three types of physique to be identified. At the $\mathrm{W} / \mathrm{H}$ index $<0.8$, the body type is considered gynoid; $>0.9$ - android, while it is transition type if the index falls between 0.8 and 0.9 . The $\mathrm{W} / \mathrm{H}$ index has a statistically significant increase $(\mathrm{p}=0.001)$ from 0.69 in Group I to 0.75 in Group II, and continues to grow up to Group IV. However, the differences are statistically insignificant $(p>0.05)$. In adolescence, all the girls had the gynoid body type; the females aged 21-30, too, mostly belonged to the gynoid type (78.0\%); $19.5 \%$ of the participants had the transition type of the body, while in some cases $(2.5 \%)$ the body type could be described as android. The females above 30 , showed a decrease in the gynoid body type share along with an increase in the number of those with the transition and android types. The endomorphy index had an average statistically significant increase from 1.07 in Group I to 1.61 (by 33.5\%, $\mathrm{p}=0.01$ ) in Group II, to 2.45 (by 34.3\%, $\mathrm{p}=0.003)$ in Group III, while there were no statistically significant differences between Groups III and IV $(p=0.6)$ observed. The intergroup differences in the exo- and mesomorphy indicators in Groups I-III were also statistically significant $(\mathrm{p}<0.05)$, and these indicators were to get stabile in Group IV $(p>0.05)$. If we accept the endomorphy index in the age groups as 1.0 , then the ratio of the endo-, ecto- and mesomorphy components will be respectively as follows: 1.0:5.8:4.0; $1.0: 4.0: 2.7 ; 1.0: 2.8: 1.8 ; 1.0: 2.6: 1.7$. It is obvious that the relative values of the exo- and mesomorphia decrease along with age.

Over age, females undergo change not only in the total body dimensions and somatotype indicators, yet also in the number and strength of the correlations between the parameters. In Group I, there was no significant correlation of the $\mathrm{W} / \mathrm{H}$ index with the BMI and the indicators of endo-, exo- and mesomorphy identified ( $p>0.05)$; significant correlation was to be observed between the BMI and the indicators of exoand mesomorphy, as well as between the indicator of endomorphy and the indicators of exo- and mesomorphy. Following every 10 years, the strength of direct correlation increased; in the general sampling, the correlations are overall stronger when compared among the groups. Of the overall body dimensions, the least variable feature was body length - the variability coefficient through the age groups varied little (from 3.1 to 3.8; low). Exo- and mesomorphy indicators had low variability ( $\mathrm{Cv} \%$ being 8.8 and 5.5 , respectively). The $\mathrm{BW}(\mathrm{Cv} \%$ from 12.8 to 24.9$)$, the BMI $(\mathrm{Cv} \%=22.7)$, the $\mathrm{W} / \mathrm{H}$ index $(\mathrm{Cv} \%=10.1)$ revealed average variability, while the variability coefficient in the endomorphy index exceeded the average value $(\mathrm{Cv} \%=32.4)$.

\section{O N CLUS\|ON}

The total body dimensions, such as the BW, the waist and hip circumference, the endo-, exo- and mesomorphy indicators increase significantly through the age period of 18 to 40 to get stable in Group IV, except for the BL, which changed slightly with the age (there 
were no statistically significant differences identified in the groups). The BMI increased, too, until the age of 40 , and then stabilized, while the $\mathrm{W} / \mathrm{H}$ index showed a statistically significant increase only between Groups I and II, and then also went on increasing, yet the differences did not reach statistical significance. Over age, following an increase in the $\mathrm{BMI}$, the $\mathrm{W} / \mathrm{H}$ index increased, so the number of people with excessive BW, obesity, as well as the number of those belonging to the intermediate and android body types, increased.

\section{REFERENCES}

1. Anisimova, E.A. Dependence of the body mass index of women on the type of physique and age / E.A. Anisimova, D.I. Anisimov // Scientific Almanac. - 2015. - No. 4 (6). - PS. 208-215. - DOI: 10.17117 / na.2015.04.208 ISSN 2411-7609.

2. Bioimpedance screening of the population of Russia in Health Centers: the prevalence of overweight and obesity / N.P. Sobolev, S.G. Rudnev, D.V. Nikolaev, T.A. Erokova, V.A. Kolesnikov, O.A. Melnichenko, E.G. Ponomareva, O.A. Starunova, M.A. Sterlikov // Russian medical journal. - 2014. - No. 4. - P. 4-13.

3. Bukavneva, NS Constitutional features of patients with alimentary dependent pathology / N.S. Bukavneva, D.B. Nikityuk // Morphological statements. - 2008. - No. 1-2. - P. 145-146.

4. Age-related variability of body composition in women / N.N. Tyatenkova, Yu.E. Uvarova, O.S. Aminova, S.V. Yakovlev // Morphology. - 2018. - T. 154, No. 4. P. 76-81.

5. Diagnostic capabilities of non-invasive bioimpedance measurement / Yu.V. Tornuev, D.L. Nepomnyashikh, D.B. Nikityuk, G.A. Lapiy, O.P. Molodykh, R.D. Nepomnyashikh, E.V. Koldysheva, Yu.M. Krinitsyna, S.M. Balakhnin, R.A. Manvelidze, D.E. Semenov, B.V. Churin // Fundamental research. - 2014. - No. 10-4. - P. 782-788.

6. Lectures on medical anthropology / O.Yu. Aleshkina, A.A. Zaichenko, E.A. Anisimova, T.M. Zagorovskaya: study guide. Saratov: Publishing house of SSMU, 2014. - 116 p.

7. Practical anthropology. Part 1. Directions of anthropology, research methods, growth and development, constitutions / O.Yu. Aleshkina, A.A. Zaichenko, E.A. Anisimova, T.M. Zagorovskaya: study guide. Saratov: SSMU Publishing House, 2014 - 120 p.

8. Sineglazova, A.V. Clinical anthropometry and constitutional biotypology / A.V. Sineglazova, O.F. Kalev: a guide for doctors. Chelyabinsk: Publishing house "Chelyabinsk State Medical Academy", 2008. - 60 p.

9. Stolyarenko, V.E. Anthropology is a systemic science of man / V.E. Stolyarenko, L. D. Stolyarenko. Rostov-on-Don: Phoenix Publishing House, 2004. $384 \mathrm{p}$.

10. Comparison of the associations of body mass index and measures of central adiposity and fat mass with coronary heart disease, diabetes, and all-cause mortality: a study using data from 4 UK cohorts / A.E. Taylor, S. Ebrahim, Y. Ben-Shlomo, R.M. Martin, P.H. Whincup, J.W. Yarnell, S.G. Wannamethee, D.A. Lawior // Amer. J. Clin. Nutr. - 2010. - Vol. 91, № 3. - P. 547-556.

11. Dmitrienko S.V. Analytical approach within cephalometric studies assessment in people with various somatotypes // Archiv EuroMedica. 2019. Vol. 9; 3: 103-111. https://doi.org/10.35630/2199$885 \mathrm{X} / 2019 / 9 / 3.29$

12. KorobkeEv A. A. Variability of odontometric indices in the aspect of sexual dimorphism. Medical News of North Caucasus. 2019;14(1.1):103-107. DOI - https://doi.org/10.14300/mnnc.2019.14062 (In Russ.).

13. Dmitrienko S. Modern $x$-ray diagnostics potential in studying morphological features of the temporal bone mandibular fossa // Archiv EuroMedica. 2020. Vol. 10. № 1. P. 116-125. https://doi. org/10.35630/2199-885X/2020/10/36

14. Domenyuk D. Structural arrangement of the temporomandibular joint in view of the constitutional anatomy // Archiv EuroMedica. 2020. Vol. 10. № 1. P. 126-136. https://doi.org/10.35630/2199$885 \mathrm{X} / 2020 / 10 / 37$

15. Harutyunyan Yu. Undifferentiated connective tissue dysplasia as a key factor in pathogenesis of maxillofacial disorders in children and adolescents // Archiv EuroMedica. 2020. Vol. 10; 2: 83-94. https://dx.doi. org/10.35630/2199-885X/2020/10/2.24

16. Shkarin V.V., Ivanov S.Yu. Morphological specifics of craniofacial complex in people with varioustypes of facial skeleton growth in case of transversal occlusion anomalie // Archiv EuroMedica. 2019. Vol. 9; 2: 5-16. https://doi.org/10.35630/2199-885X/2019/9/2/5 